\title{
Remnant Lipoproteins Are Residual Risk Factor for Future Cardiovascular Events in Patients With Stable Coronary Artery Disease and On-Statin Low-Density Lipoprotein Cholesterol Levels $<70 \mathrm{mg} / \mathrm{dL}$
}

\author{
Yuki Fujihara, MD; Takamitsu Nakamura, MD, PhD; Takeo Horikoshi, MD; \\ Jun-ei Obata, MD, PhD; Daisuke Fujioka, MD, PhD; Yosuke Watanabe, MD, PhD; \\ Kazuhiro Watanabe, MD, PhD; Kiyotaka Kugiyama, MD, PhD
}

\begin{abstract}
Background: This study examined the predictive value of remnant lipoprotein levels for cardiovascular events (CVEs) in patients with stable coronary artery disease (CAD) and low-density lipoprotein cholesterol (LDL-C) levels $<70 \mathrm{mg} / \mathrm{dL}$ on statin treatment.

Methods and Results: Serum levels of remnant lipoproteins (remnant-like lipoprotein particles cholesterol: RLP-C) were measured by an immunoseparation method in 247 consecutive patients with CAD who had on-statin LDL-C levels $<70 \mathrm{mg} / \mathrm{dL}$. All the patients were followed prospectively for a period of $\leq 60$ months or until the occurrence of the primary composite endpoint of cardiac death, nonfatal myocardial infarction, unstable angina requiring coronary revascularization, worsening heart failure, peripheral artery disease, aortic event, and ischemic stroke. During a mean follow-up period of 38 months, 33 CVEs occurred. Kaplan-Meier analysis demonstrated that higher RLP-C levels ( $\geq 3.9 \mathrm{mg} / \mathrm{dL}$, determined by ROC curve) resulted in a significantly higher probability for the primary endpoint than did lower RLP-C levels $(<3.9 \mathrm{mg} / \mathrm{dL})(\mathrm{P}<0.01$ by log-rank test). Stepwise multivariate Cox proportional hazard analysis showed that RLP-C was a significant predictor of the primary endpoint after adjustment for known risk factors and lipid variables including triglycerides, and total apolipoprotein B (hazard ratio 1.62, 95\% confidence interval 1.26-2.07, $\mathrm{P}<0.01$ ).
\end{abstract}

Conclusions: RLP-C levels are a residual risk factor for future CVEs in patients with CAD and on-statin LDL-C $<70 \mathrm{mg} / \mathrm{dL}$.

Key Words: Cardiovascular events; Hypercholesterolemia; Prognosis; Risk factors; Statins

$\mathbf{T}$ he European and AHA/ACC Guidelines recommend a lower target of low-density lipoprotein cholesterol (LDL-C) $<70 \mathrm{mg} / \mathrm{dL}$ in very high risk patients. ${ }^{1,2}$ Although LDL-C lowering by statin and/or non-statin therapies greatly reduces cardiovascular disease (CVD) risk, a considerable residual risk of CVD persists despite on-treatment LDL-C $<70 \mathrm{mg} / \mathrm{dL} \cdot{ }^{36}$ This residual risk can be classified into lipid-related and non-lipidrelated. Part of the lipid-related residual risk is thought to be attributed to triglyceride (TG)-rich lipoproteins (TGLs), ${ }^{7-11}$ which include chylomicrons, very low-density lipoproteins (VLDL), and the products of their hydrolysis, remnant lipoproteins. TGLs bind to arterial endothelium where lipoprotein lipase initiates TG hydrolysis, leading to the production of remnant lipoproteins. Remnant lipoproteins can enter the deeper structures of the arterial wall ${ }^{12}$ and be taken up by macrophages, causing foam cell formation..$^{13}$ It is not yet established, however, as to how these specific lipoprotein fractions are responsible for the lipidrelated residual risk in patients with on-statin LDL-C
$<70 \mathrm{mg} / \mathrm{dL}$.

As TGLs are not measured readily in clinical practice, the NCEP Guidelines recommend non-high-density lipoprotein cholesterol (HDL-C) measurement as a secondary target of lipid-lowering therapy once the LDL-C goal has been achieved in patients with hypertriglyceridemia. ${ }^{14}$ Non-HDL-C levels may vary as a function of cholesterol content per lipoprotein particle, and LDL particle numbers may still be high even in patients treated with statins. ${ }^{15}$ As LDL, intermediate-density lipoproteins (IDL), VLDL, chylomicrons, and remnants of VLDL and chylomicron particles each carry only 1 apolipoprotein B (ApoB-100 or ApoB-48) molecule, the total ApoB (ApoB-100+ApoB-48) value represents the total number of potentially atherogenic lipoproteins, whereas non-HDL-C provides the cholesterol content of the same lipoproteins. In this context, total ApoB may be a better indicator of residual coronary artery disease (CAD) risk than non-HDL-C.7,10

In the past, it has been difficult to assay remnant lipoproteins because of their heterogeneous nature. However,

Received January 17, 2019; revised manuscript received February 16, 2019; accepted March 6, 2019; J-STAGE Advance Publication released online April 18, 2019 Time for primary review: 26 days

Department of Internal Medicine II, University of Yamanashi, Faculty of Medicine, Chuo, Japan

Mailing address: Kiyotaka Kugiyama, MD, PhD, Department of Internal Medicine II, University of Yamanashi, Faculty of Medicine, 1110 Shimokato, Chuo 409-3898, Japan. E-mail: kugiyama@yamanashi.ac.jp

ISSN-1346-9843 All rights are reserved to the Japanese Circulation Society. For permissions, please e-mail: cj@j-circ.or.jp 
a simple and reliable technique for measuring remnant-like lipoprotein particle cholesterol (RLP-C) using an immunoseparation method has been developed. ${ }^{16,17} \mathrm{We}$ have previously shown that RLP-C levels are an important predictor of secondary CVD events in patients with hypertriglyceridemia. ${ }^{18-21}$ The present study prospectively examined whether RLP-C levels predict the risk of future CVD events (CVEs) in patients with CAD who had achieved LDL-C levels $<70 \mathrm{mg} / \mathrm{dL}$ during statin therapy.

\section{Methods}

\section{Patients}

This study enrolled 292 consecutive patients with stable CAD who had LDL-C levels $<70 \mathrm{mg} / \mathrm{dL}$ on statin treatment during $\geq 3$ months prior to enrollment. They were admitted to the cardiology section of Yamanashi University Hospital from January 1, 2008 to March 31, 2015, and had routine measurement of lipid parameters including RLP-C at enrollment. The exclusion criteria were: (1) acute coronary syndrome, stroke, cardiogenic shock, pulmonary edema, major surgery, trauma or serious infectious disease within 4 weeks prior to enrollment, (2) neoplasm, significant hepatic or inflammatory disease, (3) chronic renal failure or serum creatinine level $>2.5 \mathrm{mg} / \mathrm{dL}$, congestive heart failure (HF), or left main trunk disease, (4) other serious diseases, and (5) age $>80$ years. A total of 36 patients were excluded on the basis of these criteria, and the final study group comprised 256 patients. All the patients were ethnic Japanese and had stable CAD with no episodes of angina at rest and no change in the frequency of angina in response to sublingual nitroglycerin in the previous 3 months. All gave written informed consent at enrollment. The study was approved by the Ethics Committee of Yamanashi University Hospital. The investigation conformed to the principles outlined in the 1975 Declaration of Helsinki.

\section{Follow-up Study}

All study patients received statin treatment and the standard medical treatment for stable CAD, ${ }^{22}$ as outlined in Table 1. Types and doses of statins depended on the attending doctors. The patients also made lifestyle modifications. During the follow-up period, all patients continued with statin treatment and other medications they had been taking at the time of final enrollment. After baseline data had been obtained at the study hospital, all patients were followed prospectively every month by the patients' primary physicians at a hospital for up to 60 months or until the occurrence of a CVE: cardiac death, nonfatal myocardial infarction (MI), unstable angina pectoris (UAP) with coronary revascularization, worsening HF, peripheral artery disease (PAD) requiring endovascular or surgical treatment or amputation, aortic dissection, aortic aneurysm requiring endovascular or surgical treatment, or ischemic stroke. The time to the first event was evaluated prospectively. The primary endpoint was a composite of these events. Cardiac death was confirmed by hospital records. MI and UAP were diagnosed according to the AHA/ACC Guidelines, ${ }^{23,24}$ and their presence was confirmed by coronary angiography in all patients. HF was defined as resting dyspnea with progressive fluid retention requiring hospitalization and treatment with an intravenous diuretic. The diagnosis of ischemic stroke was based on medical history, physical examination, and brain com- puted tomography or magnetic resonance imaging. Data were obtained every 3 months from the patients' primary physicians and then collated by investigators who were blinded to each patient's status at enrollment. All endpoint data were checked for accuracy, consistency, and completeness by other investigators who also had no information on the baseline characteristics of the patients.

\section{Laboratory Assays and Measurements}

Venous blood was collected after a 12-h fast. Serum was stored at $4^{\circ} \mathrm{C}$ and used for the assays within 3 days of sampling. Fasting serum total cholesterol (TC) and TG concentrations were measured enzymatically, while serum HDL-C concentration was measured by heparin- $\mathrm{Ca}^{2+} / \mathrm{Ni}^{2+}$ precipitation. Non-HDL-C was calculated TC minus HDL-C. LDL-C levels were calculated by the Friedewald formula. If TG levels were $\geq 400 \mathrm{mg} / \mathrm{dL}$, LDL-C levels were measured by direct assay. Levels of total ApoB were determined by immuno-turbidimetric assays (Daiichi Chemicals, Tokyo, Japan). Apolipoprotein AI (ApoA-I) levels were measured by the turbidimetric immunoassay system of Daiichi Pure Chemicals (Tokyo, Japan). RLP-C levels were measured using an immunoseparation assay as previously described. ${ }^{16-21}$ Intra- and interassay coefficients of variation of RLP-C levels were $2.3 \%$ and $3.6 \%$, respectively. Left ventricular ejection fraction (LVEF) was measured by echocardiography using the Teicholz formula. ${ }^{25}$

\section{Statistical Analysis}

All data are expressed as mean $\pm \mathrm{SD}$, median and interquartile range (25th and 75 th percentiles), or frequency $(\%)$. The Shapiro-Wilk test showed that age, body mass index (BMI), hemoglobin Alc (HbAlc), C-reactive protein (CRP), B-type natriuretic peptide (BNP), LVEF, TC, TG, HDL-C, LDL-C, non-HDL-C, ApoA-I, ApoB, lipoprotein (a) [Lp(a)], and RLP-C were not distributed normally, and were therefore expressed as the median and interquartile range (25th and 75 th percentiles). Continuous variables were compared between groups using an unpaired t-test or the Mann-Whitney U-test, as appropriate. Frequencies were compared using the Chi-square test or Fisher's exact test. Spearman's rank correlation test was used for correlations between variables that were not distributed normally. The predictive value of the variables was assessed by univariate or stepwise multivariate Cox proportional hazards analyses. Multivariate Cox proportional hazards analysis was performed using confounders that were significant in the univariate model. The univariate and multivariate Cox proportional hazards analyses examined 1-SD increases in continuous variables. The presence of dichotomous variables was coded as 1 and the absence as 0. Kaplan-Meier survival analysis was used to compare 2 groups using the cutoff level of RLP-C, non-HDL-C, or TG.

$\mathrm{C}$-statistics that incorporated receiver-operating characteristic (ROC) curve analysis were used to examine the additive effects of RLP-C, total ApoB, non-HDL-C, or TG on the predictive value of the baseline model consisting of traditional CVD risk factors, which included age, male sex, hypertension (defined as $\geq 140 / 90 \mathrm{mmHg}$ or use of antihypertensive medication), current smoking, diabetes mellitus (defined by the American Diabetes Association or use of antidiabetic medication), ${ }^{26}$ and LDL-C, and HDL-C levels. We also performed category-free net reclassification improvement (NRI) and integrated discrimination improvement (IDI) to analyze the degree to which the addition of 


\begin{tabular}{|c|c|c|c|c|}
\hline & $\begin{array}{l}\text { All patients } \\
(\mathrm{n}=\mathbf{2 4 7})\end{array}$ & $\begin{array}{l}\text { Without event } \\
\quad(n=214)\end{array}$ & $\begin{array}{l}\text { With event } \\
\quad(n=33)\end{array}$ & $P$ value \\
\hline Age, years & $67(60-74)$ & $67(59-74)$ & $70(64-77)$ & 0.11 \\
\hline Male sex, n (\%) & $225(91)$ & $195(91)$ & $30(91)$ & 1.00 \\
\hline Hypertension, n (\%) & $191(77)$ & $166(78)$ & $25(76)$ & 0.99 \\
\hline Current smoking, n (\%) & $63(26)$ & $48(22)$ & $15(45)$ & $<0.01$ \\
\hline Diabetes mellitus, n (\%) & $107(43)$ & $89(42)$ & $18(55)$ & 0.23 \\
\hline Multivessel CAD, n (\%) & $152(62)$ & $131(61)$ & $21(64)$ & 0.94 \\
\hline Previous MI, n (\%) & $141(57)$ & $123(57)$ & $18(55)$ & 0.90 \\
\hline $\mathrm{BMI}, \mathrm{kg} / \mathrm{m}^{2}$ & $23.6(22-26)$ & $23.6(22-26)$ & $23.6(21-25)$ & 0.35 \\
\hline $\mathrm{HbA} 1 \mathrm{c}, \%$ & $6.3(5.8-6.9)$ & $6.2(5.8-6.7)$ & $6.8(6.1-7.5)$ & 0.03 \\
\hline $\mathrm{CRP}, \mathrm{mg} / \mathrm{dL}$ & $0.06(0.02-0.17)$ & $0.05(0.02-0.18)$ & $0.08(0.04-0.16)$ & 0.13 \\
\hline eGFR, $\mathrm{mL} / \mathrm{min} / 1.73 \mathrm{~m}^{2}$ & $65.2 \pm 15.2$ & $65.5 \pm 16.3$ & $63.1 \pm 18.1$ & 0.44 \\
\hline BNP, pg/mL & $44(18-107)$ & $43(16-101)$ & $73(27-171)$ & 0.01 \\
\hline LVEF, \% & $62(53-70)$ & $63(54-70)$ & $57(49-70)$ & 0.30 \\
\hline $\mathrm{TC}, \mathrm{mg} / \mathrm{dL}$ & $130(120-143)$ & $130(120-142)$ & $130(122-150)$ & 0.54 \\
\hline $\mathrm{TG}, \mathrm{mg} / \mathrm{dL}$ & $118(86-183)$ & $109(84-177)$ & $159(123-222)$ & $<0.01$ \\
\hline $\mathrm{HDL}-\mathrm{C}, \mathrm{mg} / \mathrm{dL}$ & $40(35-50)$ & $40(35-51)$ & $36(32-47)$ & 0.12 \\
\hline $\mathrm{LDL}-\mathrm{C}, \mathrm{mg} / \mathrm{dL}$ & $62(56-67)$ & $62(56-67)$ & $61(54-66)$ & 0.40 \\
\hline Non-HDL-C, mg/dL & $86(79-97)$ & 85 (78-94) & $91(84-106)$ & 0.03 \\
\hline ApoA-I, mg/dL & $123(109-140)$ & $124(109-140)$ & $118(109-139)$ & 0.41 \\
\hline $\mathrm{ApoB}, \mathrm{mg} / \mathrm{dL}$ & $64(58-73)$ & $63(58-72)$ & $71(63-81)$ & 0.01 \\
\hline $\mathrm{Lp}(\mathrm{a}), \mathrm{mg} / \mathrm{dL}$ & $15(7.9-28)$ & $15(7.8-27)$ & $17(8.0-35)$ & 0.35 \\
\hline $\mathrm{RLP}-\mathrm{C}, \mathrm{mg} / \mathrm{dL}$ & $3.6(2.5-5.5)$ & $3.4(2.5-4.9)$ & $5.5(3.3-8.9)$ & $<0.01$ \\
\hline \multicolumn{5}{|l|}{ Medication, n (\%) } \\
\hline Aspirin & $238(96)$ & $206(96)$ & $32(97)$ & 1.00 \\
\hline Thienopyridine & $218(88)$ & $190(89)$ & $28(85)$ & 0.72 \\
\hline ACEI/ARB & $165(67)$ & $148(69)$ & $17(52)$ & 0.07 \\
\hline$\beta$-blocker & $95(38)$ & $82(38)$ & $13(39)$ & 1.00 \\
\hline Calcium antagonist & $155(63)$ & $139(65)$ & $16(48)$ & 0.10 \\
\hline EPA & $16(6)$ & $14(7)$ & $2(6)$ & 1.00 \\
\hline Ezetimibe & $24(10)$ & $22(10)$ & $2(6)$ & 0.75 \\
\hline Fibrates & $3(1)$ & $3(1)$ & $0(0)$ & 1.00 \\
\hline Metformin & $30(12)$ & $27(13)$ & $3(9)$ & 0.78 \\
\hline \multicolumn{5}{|l|}{ Statin } \\
\hline Atorvastatin & $95(38)$ & $83(39)$ & $12(36)$ & 0.94 \\
\hline Rosuvastatin & $116(47)$ & $101(47)$ & $15(45)$ & 1.00 \\
\hline Pravastatin & $12(5)$ & $11(5)$ & $1(3)$ & 1.00 \\
\hline Pitavastatin & $20(8)$ & $17(8)$ & $3(9)$ & 0.73 \\
\hline Simvastatin & $4(2)$ & $2(1)$ & $2(6)$ & 0.09 \\
\hline
\end{tabular}

Data are expressed as the mean value \pm SD, median and range (25th and 75th percentiles) or number (\%) of patients. $\mathrm{P}$ values, comparison between patients with and without cardiovascular events. Hypertension, defined as blood pressure $>140 / 90 \mathrm{mmHg}$, or receiving antihypertensive therapy. Diabetes mellitus defined according to the American Diabetes Association criteria or taking antidiabetic medication. ACEI, angiotensin-converting enzyme inhibitor; ApoA-I, apolipoprotein A-I; ApoB, total apolipoprotein B; ARB, angiotensin II receptor blocker; BMI, body mass index; BNP, B-type natriuretic peptide; CRP, C-reactive protein; eGFR, estimated glomerular filtration rate; EPA, eicosapentaenoic acid; HbA1c, hemoglobin A1c; HDL-C, high-density lipoprotein cholesterol; LDL-C, lowdensity lipoprotein cholesterol; Lp(a), lipoprotein (a); LVEF, left ventricular ejection fraction; MI, myocardial infarction; RLP-C, remnant-like lipoprotein particle cholesterol; TC, total cholesterol; TG, triglyceride.

each lipid variable to the baseline model of traditional CVD risk factors improved its predictive ability.

All probabilities were expressed as two-tailed values, with statistical significance inferred at $\mathrm{P}<0.05$. All confidence intervals (CI) were computed at the 95\% level. The statistical analyses were performed using STATA 10.0 (StataCorp, College Station, TX, USA).

\section{Calculation of the Sample Size}

On the basis of our preliminary observations in patients with stable CAD and on-statin LDL-C $<70 \mathrm{mg} / \mathrm{dL}$, the composite endpoint occurred in approximately $20 \%$ of patients with higher RLP-C levels $(\geq 4.5 \mathrm{mg} / \mathrm{dL})$ during 5 years of follow-up, and in $5 \%$ of patients with lower RLP-C levels $(<4.5 \mathrm{mg} / \mathrm{dL})$. To provide our two-sided statistical analyses with sufficient statistical power of 0.90 $(\beta=0.10$ and $\alpha=0.05)$, a total of 232 patients with stable 


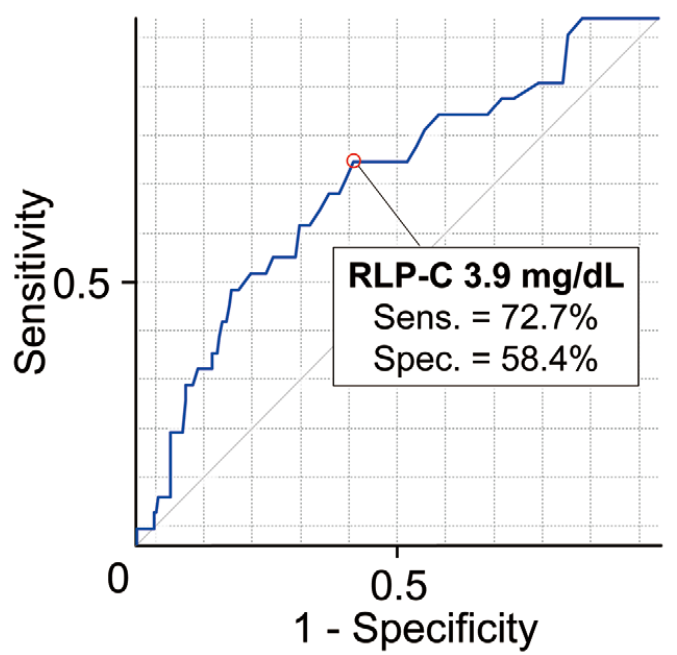

Figure 1. Receiver-operating characteristic $(\mathrm{ROC})$ curve to obtain optimal cutoff level of remnant-like lipoprotein particles cholesterol (RLP-C) for the prediction of clinical events.

CAD and on-statin LDL-C $<70 \mathrm{mg} / \mathrm{dL}$ were required for the follow-up study. A total of 256 patients gave this prospective study sufficient statistical power.

\section{Results}

We withdrew 9 patients from the study after enrollment because they could no longer be contacted; thus, 247 patients completed the follow-up study. The duration of the follow-up period ranged from 2 to 60 months (mean $38 \pm 21$ months). During the follow-up period, 33 patients had a CVE, which comprised 2 cardiac deaths, 1 AMI, 13 UAP requiring unplanned coronary revascularization, 9 worsening HF requiring hospital admission, 1 PAD requiring endovascular treatment, 3 aortic aneurysms requiring surgical treatment, and 4 ischemic strokes (Supplementary Table). The incidence of each event according to RLP-C levels is shown in Supplementary Table. The incidence of the primary composite endpoint and HF was higher in patients with high RLP-C levels than in those with low RLP-C levels (Supplementary Table).

\section{Baseline Characteristics}

The baseline characteristics of the study patients are summarized in Table 1. Compared with patients without CVE, those with an event had a higher prevalence of current smoking and higher levels of $\mathrm{HbAlc}$, BNP, TG, nonHDL-C, total ApoB, and RLP-C at baseline (Table 1). There was no significant difference in LDL-C levels between the 2 groups. The types of statin administered were similar in patients with and without events (Table 1). RLP-C levels showed significant correlations with TG $(\rho=0.80, \mathrm{P}<0.01), \mathrm{TC}(\rho=0.58, \mathrm{P}<0.01)$, total ApoB $(\rho=0.55$, $\mathrm{P}<0.01)$, and non-HDL-C $(\rho=0.70, \mathrm{P}<0.01)$, but not with LDL-C $(\rho=-0.09, \mathrm{P}=0.17)$.

\section{Predictive Value of RLP-C}

ROC curve analysis showed that the cutoff value for RLP-C level was $3.9 \mathrm{mg} / \mathrm{dL}$ (Figure 1), with a sensitivity of

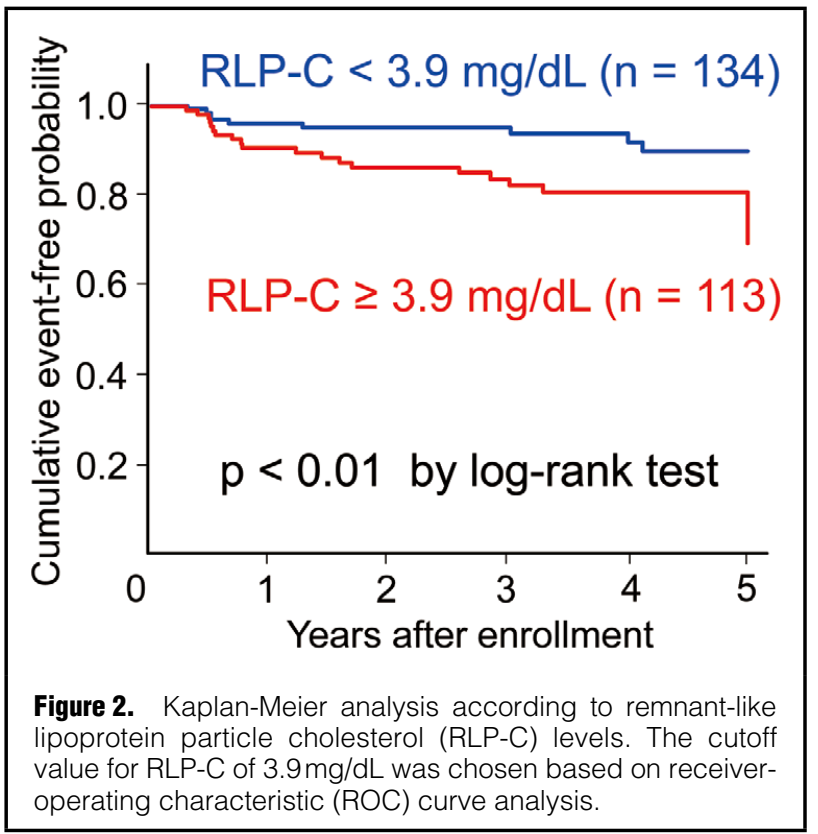

$72.7 \%$ and specificity of $58.4 \%$ for predicting future CVEs. When the patients were stratified into 2 groups using the RLP-C cutoff value, Kaplan-Meier analysis showed that patients with high levels of RLP-C $(\geq 3.9 \mathrm{mg} / \mathrm{dL})(\mathrm{n}=113)$ had a higher probability of future CVEs than those with lower levels $(<3.9 \mathrm{mg} / \mathrm{dL} ; \mathrm{n}=134, \mathrm{P}<0.01$, log-rank test; Figure 2). Univariate Cox proportional hazard analysis showed current smoking (hazard ratio (HR): 2.50; 95\% CI: $1.25-5.00$ ), HbAlc (HR: 1.32; 95\% CI: 1.01-1.73), TG (HR: 1.51; 95\% CI 1.13-2.02), total ApoB (HR:1.47; 1.02-2.12), Lp(a) (HR: 1.31; 95\% CI: 1.01-1.71), and RLP-C (HR: 1.54; 95\% CI: 1.22-1.96) were significant predictors for CVEs (Table 2). As shown in Table 2, high levels of RLP-C (HR: 1.62; 95\% CI: 1.26-2.07) and current smoking (HR: 2.39; 95\% CI: 1.18-4.87) remained significant predictors of CVEs in the multivariate Cox proportional hazard analysis. In the Kaplan-Meier analysis, higher levels of TG $(\geq 118 \mathrm{mg} / \mathrm{dL}$, determined by ROC curve analysis) resulted in a higher probability of future CVEs than those with lower levels $(<118 \mathrm{mg} / \mathrm{dL})$ (Supplementary Figures 1,2), but higher non-HDL-C levels $(\geq 86 \mathrm{mg} / \mathrm{dL}$, determined by ROC curve) did not (Supplementary Figures 3,4).

\section{Incremental Effect of RLP-C on Predictive Value of Traditional Risk Factors}

The addition of RLP-C had a significant incremental effect on the area under the ROC curve (AUC) obtained with our baseline model that consisted of traditional risk factors including age, male sex, hypertension, current smoking, diabetes mellitus, LDL-C, and HDL-C (AUC; baseline model, 0.68 vs. baseline model+RLP-C, $0.77, \mathrm{P}=0.02$ ) (Table 3). The addition of total ApoB, but not non-HDL-C and TG, also had a significant incremental effect (Table 3). The addition of RLP-C level, total ApoB, non-HDL-C, or TG to the traditional risk factors enhanced Category-free NRI and IDI (Table 4). The addition of RLP-C but not TG to the traditional risk factors+non-HDL-C+ApoB enhanced Category-free NRI and IDI (Table 4). 
Table 2. Univariate and Stepwise Multivariate Cox Hazard Analysis Models for Future Cardiovascular Events

\begin{tabular}{|c|c|c|c|c|c|c|}
\hline & \multicolumn{3}{|c|}{ Univariate analysis } & \multicolumn{3}{|c|}{ Multivariate analysis } \\
\hline & HR & $95 \% \mathrm{Cl}$ & $P$ value & HR & $95 \% \mathrm{Cl}$ & $P$ value \\
\hline Age, per 11 years & 1.44 & $0.98-2.10$ & 0.06 & & - & \\
\hline Male sex & 0.98 & $0.30-3.20$ & 0.97 & & - & \\
\hline Hypertension & 0.83 & $0.38-1.85$ & 0.65 & & - & \\
\hline Current smoking & 2.50 & $1.25-5.00$ & 0.01 & 2.39 & $1.18-4.87$ & 0.02 \\
\hline Diabetes mellitus & 1.65 & $0.83-3.28$ & 0.15 & & - & \\
\hline Multivessel disease & 1.10 & $0.54-2.23$ & 0.80 & & - & \\
\hline Previous MI & 0.89 & $0.45-1.77$ & 0.74 & & - & \\
\hline $\mathrm{BMI}$, per $3 \mathrm{~kg} / \mathrm{m}^{2}$ & 0.80 & $0.53-1.20$ & 0.28 & & - & \\
\hline eGFR, per $16 \mathrm{~mL} / \mathrm{min} / 1.73 \mathrm{~m}^{2}$ & 0.84 & $0.60-1.18$ & 0.30 & & - & \\
\hline $\mathrm{HbA} 1 \mathrm{c}$, per $1 \%$ & 1.32 & $1.01-1.73$ & 0.04 & & Not selected & \\
\hline $\mathrm{BNP}$, per $122 \mathrm{pg} / \mathrm{mL}$ & 1.19 & $0.96-1.48$ & 0.12 & & - & \\
\hline LVEF, per $12 \%$ & 0.69 & $0.46-1.04$ & 0.08 & & - & \\
\hline LDL-C, per $8 \mathrm{mg} / \mathrm{dL}$ & 0.92 & $0.60-1.41$ & 0.70 & & - & \\
\hline HDL-C, per $16 \mathrm{mg} / \mathrm{dL}$ & 0.75 & $0.47-1.20$ & 0.23 & & - & \\
\hline Non-HDL-C, per $16 \mathrm{mg} / \mathrm{dL}$ & 1.44 & $0.99-2.10$ & 0.06 & & - & \\
\hline $\mathrm{TG}$, per $87 \mathrm{mg} / \mathrm{dL}$ & 1.51 & $1.13-2.02$ & $<0.01$ & & Not selected & \\
\hline ApoA-I, per $75 \mathrm{mg} / \mathrm{dL}$ & 0.82 & $0.33-2.06$ & 0.67 & & - & \\
\hline ApoB, per $13 \mathrm{mg} / \mathrm{dL}$ & 1.47 & $1.02-2.12$ & 0.04 & & Not selected & \\
\hline ApoB/ApoA-I, per 0.2 & 1.30 & $0.95-1.77$ & 0.10 & & - & \\
\hline Lp(a), per $21 \mathrm{mg} / \mathrm{dL}$ & 1.31 & $1.01-1.71$ & 0.04 & & Not selected & \\
\hline RLP-C, per $3 \mathrm{mg} / \mathrm{dL}$ & 1.54 & $1.22-1.96$ & $<0.01$ & 1.62 & $1.26-2.07$ & $<0.01$ \\
\hline
\end{tabular}

The hazard ratio $(\mathrm{HR})$ and $95 \%$ confidence interval $(\mathrm{Cl})$ for continuous variables were estimated by a 1-SD increase (per 1-SD). Abbreviations as in Table 1.

\begin{tabular}{|c|c|c|c|}
\hline & AUC & $95 \% \mathrm{Cl}$ & $P$ value \\
\hline Traditional risk factors & 0.68 & $0.58-0.78$ & - \\
\hline+ ApoB & 0.76 & $0.67-0.86$ & 0.03 \\
\hline +Non-HDL-C & 0.74 & $0.65-0.85$ & 0.09 \\
\hline$+\mathrm{TG}$ & 0.75 & $0.65-0.85$ & 0.06 \\
\hline$+\mathrm{RLP}-\mathrm{C}$ & 0.77 & $0.67-0.88$ & 0.02 \\
\hline
\end{tabular}

Our baseline model of traditional risk factors included age, male sex, hypertension, current smoking, diabetes mellitus, LDL-C and HDL-C. AUC, area under the receiver-operating characteristic curve. Other abbreviations as in Tables 1,2.

Table 4. NRI and IDI for the Incremental Predictive Values of the Combination of Traditional Risk Factors, ApoB, Non-HDL-C, TG and RLP-C

\begin{tabular}{lcccccc} 
& \multicolumn{2}{c}{ Category-free NRI } & & \multicolumn{3}{c}{ IDI } \\
\cline { 2 - 3 } \cline { 5 - 6 } Traditional risk factors & Index & P value & & Index & & P value \\
+ApoB & - & - & & - & - \\
+Non-HDL-C & 0.49 & $<0.01$ & & 0.03 & 0.04 \\
+TG & 0.62 & $<0.01$ & & 0.05 & $<0.01$ \\
+RLP-C & 0.54 & $<0.01$ & & 0.07 & $<0.01$ \\
Traditional risk factors+non-HDL-C+ApoB & 0.89 & $<0.01$ & & 0.10 & $<0.01$ \\
$\quad$ +RLP-C & - & - & & - & - \\
+TG & 0.52 & $<0.01$ & & 0.06 & 0.02 \\
Traditional risk factors+non-HDL-C+RLP-C & 0.08 & 0.68 & & 0.03 & 0.20 \\
$\quad$ +ApoB & - & - & & - & - \\
\hline
\end{tabular}

The traditional risk factors consisted of age, male sex, hypertension, current smoking, diabetes mellitus, LDL-C and HDL-C. IDI, integrated discrimination improvement; NRI, net reclassification improvement. Other abbreviations as in Table 1. 


\section{Discussion}

The present study found that RLP-C levels are an independent predictor of CVEs in patients with CAD and onstatin treatment LDL-C $<70 \mathrm{mg} / \mathrm{dL}$. The study also demonstrated that the addition of RLP-C had an additive prognostic value to models of traditional risk factors that include non-HDL-C and ApoB. Thus, RLP-C levels have an important role in the residual risk of future CVEs in patients with stable CAD and on-statin LDL-C $<70 \mathrm{mg} / \mathrm{dL}$. It remains to be determined whether RLP remains a risk factor for CVD in patients with very low levels of LDL-C (e.g., $<30 \mathrm{mg} / \mathrm{dL}$ ) after proprotein convertase subtilisin/ kexin type 9 (PCSK9) inhibitors. The very recent AHA/ ACC Guidelines ${ }^{2}$ recommend a modified equation ${ }^{27}$ for calculation of LDL-C levels $<70 \mathrm{mg} / \mathrm{dL}$ instead of the Friedewald formula. The re-calculated results using the novel equation ${ }^{27}$ remained similar to those obtained using the Friedewald formula (data not shown).

Because the present study measured RLP from fasting serum, the fasting RLP are derived from VLDL. ${ }^{28}$ Statins cause substantial falls in LDL and a relatively modest decrease in TGLs, including VLDL and RLP. ${ }^{29,30}$ Our previous in vitro studies showed that RLP induced expression of endothelial proatherogenic molecules and endothelial vasomotor dysfunction to a several-fold greater extent compared with LDL or other TGLs. ${ }^{31,32}$ As RLP had greater atherogenicity than other TGLs, RLP-C levels remained a predictor of CVEs despite the reduction in RLP-C levels on statin treatment.

Although the NCEP Guidelines recommend non-HDL-C measurement as a secondary target of lipid-lowering therapy after the LDL-C goal has been achieved, ${ }^{\mathbf{1 4}}$ non-HDL-C includes atherogenic TGLs when TG is $>200 \mathrm{mg} / \mathrm{dL} .{ }^{14} \mathrm{As}$ the present patients had a normal range of TG levels and low non-HDL-C levels, non-HDL lipoproteins may not have included a significant level of atherogenic TGLs. Median levels of RLP-C and non-HDL-C in the present patients were $3.6 \mathrm{mg} / \mathrm{dL}$ and $86 \mathrm{mg} / \mathrm{dL}$, respectively. Thus, judging by their concentrations, the atherogenicity of RLP-C made little contribution to that of non-HDL-C.

Total ApoB levels were a predictor of the CVEs in the present study's univariate Cox proportional hazard analysis. The total ApoB concentration reflects the number of LDL and TGL particles, and the level of ApoB may not be reduced as much as expected from the reduction of LDL-C while on statin treatment. ${ }^{33}$ In this sense, total ApoB may reflect atherogenic TGLs while on statin treatment. ${ }^{7}$ However, total ApoB lost its predictability in the multivariate Cox proportional hazard analysis using covariates including RLP-C in the present study because total ApoB had a significant correlation with RLP-C. TG had significant predictability of CVEs in both the Kaplan-Meier curve analysis and univariate Cox proportional hazard analysis. And the addition of $\mathrm{TG}$ to the traditional risk factors enhanced Category-free NRI and IDI. However, TG lost its predictability in the multivariate Cox proportional hazard analysis when RLP-C was included in covariates because TG levels also had a strong correlation with RLP-C levels.

Previous reports have shown that fibrates and ezetimibe as well as statins effectively reduce RLP-C. ${ }^{34,35}$ Therefore, an increased dose of statin alone or in combination with fibrates or ezetimibe may have been needed to reduce RLP-C in the present patients. Although PCSK9 inhibi- tors cause a relatively modest reduction of TGLs, ${ }^{36}$ their effect on RLP-C levels remains unclear.

\section{Study Limitations}

First, although the current immunoseparation method for assaying RLP has been shown by us and other investigators to be useful for assessing and monitoring CVD risk in patients with hypertriglyceridemia, ${ }^{\mathbf{1 6}-21}$ the assay has economic and technical limitations for routine clinical practice in countries other than Japan and the USA. Second, the relatively small number of enrolled patients limited the statistical power of the study. Third, we did not have information regarding medication for CVD prior to enrollment in the study, which might have affected the frequency of CVEs during the follow-up period.

\section{Conclusions}

Our study showed evidence that RLP-C levels are a residual risk of future CVD in patients with stable CAD and on-statin LDL-C $<70 \mathrm{mg} / \mathrm{dL}$.

\section{Disclosure}

Dr. Kugiyama has received scholarship donations from Takeda, Daiichi Sankyo, Astellas, Boehringer Ingelheim, MSD, Boston Scientific Japan, Abbott, Medtronic, Biotronik Japan, and St Jude Medical. The other authors declare no conflicts of interest.

\section{Source of Funding}

This research was supported by the Ministry of Education, Culture, Sports, Science, and Technology, Health, Tokyo, Japan (grants-in-aid for B2-19390209 and B-22390158).

\section{References}

1. Catapano AL, Graham I, De Backer G, Wiklund O, Chapman MJ, Drexel H, et al; ESC Scientific Document Group. 2016 ESC/EAS Guidelines for the Management of Dyslipidaemias. Eur Heart J 2016; 37: 2999-3058.

2. Grundy SM, Stone NJ, Bailey AL, Beam C, Birtcher KK, Blumenthal RS, et al. 2018. AHA/ACC/AACVPR/AAPA/ABC/ ACPM/ADA/AGS/APhA/ASPC/NLA/PCNA Guideline on the Management of Blood Cholesterol: A report of the American College of Cardiology/American Heart Association Task Force on Clinical Practice Guidelines. J Am Coll Cardiol, doi:10.1016/j. jacc.2018.11.003.

3. Cannon CP, Braunwald E, McCabe CH, Rader DJ, Rouleau JL, Belder R, et al; Pravastatin or Atorvastatin Evaluation and Infection Therapy-Thrombolysis in Myocardial Infarction 22 Investigators. Intensive versus moderate lipid lowering with statins after acute coronary syndromes. $N$ Engl J Med 2004; 350: 495-504.

4. Ridker PM, Danielson E, Fonseca FA, Genest J, Gotto AM Jr, Kastelein JJ, et al; JUPITER Study Group. Rosuvastatin to prevent vascular events in men and women with elevated C-reactive protein. N Engl J Med 2008; 359: 2195-2207.

5. Sabatine MS, Giugliano RP, Keech AC, Honarpour N, Wiviott SD, Murphy SA, et al; FOURIER Steering Committee and Investigators. Evolocumab and clinical outcomes in patients with cardiovascular disease. N Engl J Med 2017; 376: 1713-1722.

6. Cannon CP, Blazing MA, Giugliano RP, McCagg A, White JA, Theroux P, et al; IMPROVE-IT Investigators. Ezetimibe added to statin therapy after acute coronary syndromes. $N$ Engl J Med 2015; 372: 2387-2397.

7. Mudd JO, Borlaug BA, Johnston PV, Kral BG, Rouf R, Blumenthal RS, et al. Beyond low-density lipoprotein cholesterol: Defining the role of low-density lipoprotein heterogeneity in coronary artery disease. J Am Coll Cardiol 2007; 50: 17351741

8. Miller M, Ginsberg HN, Schaefer EJ. Relative atherogenicity and predictive value of non-high-density lipoprotein cholesterol for coronary heart disease. Am J Cardiol 2008; 101: 1003-1008.

9. Arsenault BJ, Rana JS, Stroes ES, Després JP, Shah PK, Kastelein JJ, et al. Beyond low-density lipoprotein cholesterol: 
Respective contributions of non-high-density lipoprotein cholesterol levels, triglycerides, and the total cholesterol/high-density lipoprotein cholesterol ratio to coronary heart disease risk in apparently healthy men and women. J Am Coll Cardiol 2009; 55: $35-41$.

10. Ray KK, Cannon CP, Cairns R, Morrow DA, Ridker PM, Braunwald E. Prognostic utility of apoB/AI, total cholesterol/ HDL, non-HDL cholesterol, or hs-CRP as predictors of clinical risk in patients receiving statin therapy after acute coronary syndromes: Results from PROVE IT-TIMI 22. Arterioscler Thromb Vasc Biol 2009; 29: 424-430.

11. Havel RJ. Remnant lipoproteins as therapeutic targets. Curr Opin Lipidol 2000; 11: 615-620.

12. Zilversmit DB. Atherogenic nature of triglycerides, postprandial lipidemia, and triglyceride-rich remnant lipoproteins. Clin Chem 1995; 41: $153-158$.

13. Koo C, Wernette-Hammond ME, Garcia Z, Malloy MJ, Uauy $\mathrm{R}$, East C, et al. Uptake of cholesterol-rich remnant lipoproteins by human monocyte-derived macrophages is mediated by low density lipoprotein receptors. $J$ Clin Invest 1988; 81: 1332-1340.

14. Expert Panel on Detection, Evaluation, and Treatment of High Blood Cholesterol in Adults. Executive Summary of the Third Report of The National Cholesterol Education Program (NCEP) Expert Panel on Detection, Evaluation, And Treatment of High Blood Cholesterol In Adults (Adult Treatment Panel III). JAMA 2001; 285: 2486-2497.

15. Ballantyne CM, Raichlen JS, Cain VA. Statin therapy alters the relationship between apolipoprotein B and low-density lipoprotein cholesterol and non-high-density lipoprotein cholesterol targets in high-risk patients: The MERCURY II (Measuring Effective Reductions in Cholesterol Using Rosuvastatin) trial. $J$ Am Coll Cardiol 2008; 52: 626-632.

16. Nakajima K, Saito T, Tamura A, Suzuki M, Nakano T, Adachi $\mathrm{M}$, et al. Cholesterol in remnant-like lipoproteins in human serum using monoclonal anti apo B-100 and anti apo A-I immunoaffinity mixed gels. Clin Chim Acta 1993; 223: 53-71.

17. Leary ET, Wang T, Baker DJ, Cilla DD, Zhong J, Warnick GR, et al. Evaluation of an immunoseparation method for quantitative measurement of remnant-like particle-cholesterol in serum and plasma. Clin Chem 1998; 44: 2490-2498.

18. Kugiyama K, Doi H, Takazoe K, Kawano H, Soejima H, Mizuno Y, et al. Remnant lipoprotein levels in fasting serum predict coronary events in patients with coronary artery disease. Circulation 1999; 99: 2858-2866.

19. Nakamura T, Takano H, Umetani K, Kawabata K, Obata JE, Kitta Y, et al. Remnant lipoproteinemia is a risk factor for endothelial vasomotor dysfunction and coronary artery disease in metabolic syndrome. Atherosclerosis 2005; 181: 321-327.

20. Fukushima H, Sugiyama S, Honda O, Koide S, Nakamura S, Sakamoto T, et al. Prognostic value of remnant-like lipoprotein particle levels in patients with coronary artery disease and type II diabetes mellitus. J Am Coll Cardiol 2004; 43: 2219-2224.

21. Nakamura T, Obata JE, Takano H, Kawabata K, Sano K, Kobayashi T, et al. High serum levels of remnant lipoproteins predict ischemic stroke in patients with metabolic syndrome and mild carotid atherosclerosis. Atherosclerosis 2009; 202: 234-240.

22. Fraker TD Jr, Fihn SD; 2002 Chronic Stable Angina Writing Committee; American College of Cardiology; American Heart Association, Gibbons RJ, Abrams J, Chatterjee K, Daley J, Deedwania PC, Douglas JS, et al. 2007 chronic angina focused update of the ACC/AHA 2002 guidelines for the management of patients with chronic stable angina. J Am Coll Cardiol 2007; 50: 2264-2274.

23. Antman EM, Anbe DT, Armstrong PW, Bates ER, Green LA,
Hand M, et al. ACC/AHA guidelines for the management of patients with ST-elevation myocardial infarction: Executive summary: A report of the American College of Cardiology/American Heart Association Task Force on Practice Guidelines (Writing Committee to Revise the 1999 Guidelines for the Management of Patients With Acute Myocardial Infarction). Circulation 2004; 110: $588-636$

24. Anderson JL, Adams CD, Antman EM, Bridges CR, Califf RM, Casey DE Jr, et al. ACC/AHA 2007 guidelines for the management of patients with unstable angina/non-ST-elevation myocardial infarction. J Am Coll Cardiol 2007; 50: e1-e157.

25. Teichholz LE, Kreulen T, Herman MV, Gorlin R. Problems in echocardiographic volume determinations: Echocardiographicangiographic correlations in the presence of absence of asynergy. Am J Cardiol 1976; 37: 7-11.

26. American Diabetes Association. Standards of medical care in diabetes: 2006. Diabetes Care 2006; 29(Suppl 1): S4-S42.

27. Martin SS, Blaha MJ, Elshazly MB, Toth PP, Kwiterovich PO, Blumenthal RS, et al. Comparison of a novel method vs the Friedewald equation for estimating low-density lipoprotein cholesterol levels from the standard lipid profile. JAMA 2013; 310: 2061-2068.

28. Kugiyama K, Doi H, Motoyama T, Soejima H, Misumi K, Kawano H, et al. Association of remnant lipoprotein levels with impairment of endothelium-dependent vasomotor function in human coronary arteries. Circulation 1998; 97: 2519-2526.

29. Packard CJ. Determinants of achieved LDL cholesterol and "non-HDL" cholesterol in the management of dyslipidemias. Curr Cardiol Rep 2018; 20: 60.

30. Schaefer EJ, McNamara JR, Tayler T, Daly JA, Gleason JA, Seman LJ, et al. Effects of atorvastatin on fasting and postprandial lipoprotein subclasses in coronary heart disease patients versus control subjects. Am J Cardiol 2002; 90: 689-696.

31. Doi H, Kugiyama K, Ohgushi M, Sugiyama S, Matsumura T, Ohta Y, et al. Remnants of chylomicron and very low density lipoprotein impair endothelium-dependent vasorelaxation. Atherosclerosis 1998; 137: 341-349.

32. Doi H, Kugiyama K, Oka H, Sugiyama S, Ogata N, Koide SI, et al. Remnant lipoproteins induce proatherothrombogenic molecules in endothelial cells through a redox-sensitive mechanism. Circulation 2000; 102: 670-676.

33. Ballantyne CM, Bertolami M, Hernandez Garcia HR, Nul D, Stein EA, et al. Achieving LDL cholesterol, non-HDL cholesterol, and apolipoprotein B target levels in high-risk patients: Measuring Effective Reductions in Cholesterol Using Rosuvastatin therapY (MERCURY) II. Am Heart J 2006; 151: 975.e1 -e9.

34. Sano K, Nakamura T, Hirano M, Kitta Y, Kobayashi T, Fujioka D, et al. Comparative study of bezafibrate and pravastatin in patients with coronary artery disease and high levels of remnant lipoprotein. Circ J 2010; 74: 1644-1650.

35. Nakamura T, Hirano M, Kitta Y, Fujioka D, Saito Y, Kawabata $\mathrm{K}$, et al. A comparison of the efficacy of combined ezetimibe and statin therapy with doubling of statin dose in patients with remnant lipoproteinemia on previous statin therapy. J Cardiol 2012; 60: 12-17.

36. Dijk W, Le May C, Cariou B. Beyond LDL: What role for PCSK9 in triglyceride-rich lipoprotein metabolism? Trends Endocrinol Metab 2018; 29: 420-434.

\section{Supplementary Files}

Please find supplementary file(s);

http://dx.doi.org/10.1253/circj.CJ-19-0047 